\title{
Organic dust-induced interleukin-12 production activates T- and natural killer cells
}

\author{
C. Müller-Suur*, K. Larsson\#, J. Grunewald*
}

\begin{abstract}
Organic dust-induced interleukin-12 production activates $T$ - and natural killer cells. C. Müller-Suur, K. Larsson, J. Grunewald. (C) ERS Journals Ltd 2002.

ABSTRACT: Exposure in swine confinement buildings causes intense airway inflammation and lymphocyte activation, as assessed by bronchoalveolar lavage. To further clarify the T-cell activation, the present in vitro study focused on intracellular cytokine production following exposure to organic dust from swine houses.

Whole blood from healthy donors was incubated with swine dust, phytohaemagglutinin (positive control) or Roswell Park Memorial Institute 1640 medium (negative control), and the production of intracellular interferon (IFN)- $\gamma$, tumour necrosis factor (TNF)- $\alpha$, interleukin (IL)-4 and IL-12 was analysed by flow cytometry. Cells were double stained for specific cell surface markers on T-cells (CD3+, CD4+, CD8+), natural killer (NK) cells (CD56+CD16 + ) and monocytes (defined as CD14 + cells).

Following $1 \mathrm{~h}$ of incubation of whole blood with swine dust, CD14+ cells produced high levels of TNF- $\alpha$ and IL-12, whereas CD3,+ CD4 + and CD8 + T-cells and $\mathrm{CD56}+\mathrm{CD16}+\mathrm{NK}$ cells required a longer incubation time $(22 \mathrm{~h})$ to produce IFN- $\gamma$ and TNF- $\alpha$. When antibodies that block the IL-12 receptor were added to whole blood incubated with swine dust, NK cell production of IFN- $\gamma$ was attenuated and CD69 expression on $\mathrm{CD3}+$ cells decreased.

In conclusion, this study indicates that swine dust can, at least in part, stimulate phagocytic cells to activate natural killer cells and T-lymphocytes through the production of interleukin-12.

Eur Respir J 2002; 20: 686-690.
\end{abstract}

\begin{abstract}
*Dept of Medicine, Division of Respiratory Medicine, Lung Research Laboratory L2:01, Karolinska Hospital, and ${ }^{\#}$ Lung and Allergy Research, the Institute of Environmental Medicine, Karolinska Institutet, Stockholm, Sweden.
\end{abstract}

Correspondence: C. Müller-Suur Dept of Medicine

Division of Respiratory Medicine Lung Research Laboratory L2:01 Karolinska Hospital

17176 Stockholm

Sweden

Fax: 46851775451

E-mail: lotta.muller-suur@ks.se

Keywords: Intracellular cytokines lymphocyte stimulation organic dust

Received: March 122002

Accepted after revision: April 232002
The present authors have previously demonstrated that exposure to dust in a swine confinement facility induces activation of $\mathrm{T}$-cells in vivo, as assessed by analyses of cells obtained through bronchoalveolar lavage [1]. The authors have also shown that T-cells in whole blood exposed to dust in vitro express the activation markers CD69, CD25 and human leucocyte antigen-DR in a dose- and time-dependent manner [2]. Plasma obtained from blood that had been incubated with dust for $24 \mathrm{~h}$, i.e. "conditioned plasma", induced a high CD69 expression on T-cells (CD3+) in whole blood [3]. Since no increased CD69 expression on T-cells was observed in blood depleted from phagocytic cells, and since an increased production of interleukin (IL)-12 and interferon interferon (IFN)$\gamma$ was detected in whole blood stimulated with swine dust, the authors suggested that soluble mediators derived from phagocytic cells may be responsible for the lymphocyte activation.

It is known that cytokines, such as tumour necrosis factor (TNF)- $\alpha$ and IL-12, are capable of inducing T-cell activation [4, 5]. IL-12 is produced by activated monocytes but also by other antigen-presenting cells and neutrophils, and it has pleiotropic effects on T-cells and natural killer (NK) cells [6]. The aim of the present study was to investigate whether swine dust could induce phagocytic cells (CD14+ monocytes) to produce the cytokines TNF- $\alpha$ and IL-12 and/or T- and
NK cells to produce TNF- $\alpha$, IFN- $\gamma$ and IL-4. In addition, the authors wanted to clarify the role of IL-12 in lymphocyte activation by using of IL-12 receptor blocking antibodies.

\section{Materials and methods}

\section{Subjects}

Venous blood was collected from 10 (two males) nonallergic, nonsmoking, healthy subjects, with a mean age of 44 yrs (range 27-60). All subjects gave their informed consent and the study was approved by the Ethics Committee of Karolinska Institutet, Stockholm, Sweden.

\section{Stimulation with dust}

Dust was collected in a swine confinement building $\sim 1.5 \mathrm{~m}$ above the ground and dissolved in Roswell Park Memorial Institute (RPMI) 1640 medium (Gibco Laboratories, Paisley, UK), sonicated for $10 \mathrm{~min}$ and diluted in whole blood to a final concentration of $100 \mu \mathrm{g} \cdot \mathrm{mL}^{-1}$. The polyclonal activator, phytohaemagglutinin (PHA), used as positive control in $\mathrm{T}$ - and NK cell analysis, was also dissolved in 
RPMI 1640, sonicated for $10 \mathrm{~min}$ and diluted in whole blood to a final concentration of $10 \mu \mathrm{g} \cdot \mathrm{mL}^{-1}$. Unstimulated whole blood containing RPMI 1640 was used as negative control.

\section{Staining of surface markers and intracellular cytokines}

For analyses of monocytes (CD14+ cells) $(n=6)$, whole blood was incubated for $1 \mathrm{~h}$ with dust or RPMI 1640 in the presence of brefeldin A (Golgi Plug ${ }^{\text {TM}}$; PharMingen, San José, CA, USA). Brefeldin A inhibits the intracellular transport, implying that cytokines produced during the activation are intracellularly retained (protocol according to the manufacturer).

For lymphocyte analyses $(n=10)$, whole blood was diluted 1:1 with RPMI containing L-glutamine and incubated for $12 \mathrm{~h}$ with swine dust or PHA followed by an additional $10-\mathrm{h}$ incubation in the presence of $1 \mu \mathrm{g}$ brefeldin $\mathrm{A} \cdot \mathrm{mL}$ blood $^{-1}$. All incubations were performed at $37^{\circ} \mathrm{C}$ in the presence of $5 \%$ carbon dioxide.

After stimulation, red blood cells were lysed (PharmLyse; PharMingen) and washed with staining buffer (phosphate buffered saline (PBS) containing $1 \%$ foetal calf serum). The cells were centrifugated to a pellet at $500 \times g$ for $5 \mathrm{~min}$, the supernatant was aspirated and cells $\left(\sim 200 \times 10^{3}\right)$ were diluted in $100 \mu \mathrm{L}$ staining buffer. The respective cell subset and/or activation marker-specific monoclonal antibody (Mab) was added and incubated for $30 \mathrm{~min}$, washed in staining buffer and then fixed and permeabilised by adding Cytofix/Cytoperm solution (PharMingen) for $20 \mathrm{~min}$. Cells were then washed with Perm/Wash solution (PharMingen) and incubated for $10 \mathrm{~min}$ at room temperature (RT) in the dark. They were then centrifuged for $5 \mathrm{~min}$ at $500 \times g$. The supernatant was aspirated and the cell pellet was resuspended in Perm/ Wash solution containing cytokine-specific Mab for intracellular staining and incubated for $30 \mathrm{~min}$ at RT in the dark. Cells were washed with Perm/Wash solution (without Mab) and thereafter centrifuged for $5 \mathrm{~min}$ at $500 \times \mathrm{g}$. The supernatant was aspirated and the cells were resuspended in PBS containing 4\% formaldehyde (Cellfix; Becton Dickinson, San José, CA, USA). The cells were then analysed by flow cytometry.

In a second experimental set up $(n=6)$, a combination of the Mabs 2.4E6 and 2B10 (PharMingen) directed to the IL-12 receptor $\beta 1$ subunit, were used to block the human IL-12 receptor [7]. Blocking antibodies or isotype controls (mouse immunoglobulin (Ig)G1 and rat IgG2a; PharMingen) were added $1 \mathrm{~h}$ prior to dust incubation. Cells were then incubated with dust, PHA or RPMI. Cytokine production by T- and NK cells as well as T-cell CD69 expression were investigated with and without IL-12 receptor blocking Mab.

\section{Monoclonal antibodies and flow cytometric analysis}

Cells were characterised by subgroup specific fluorochrome conjugated Mab. For identification of
T-cells, CD3, CD4, CD8-peridinin clorophyll protein (PerCP) conjugated Mab (Becton Dickinson) were used, while NK cells were identified using CD56+ CD16+-phycoerythrin (PE) conjugated Mab (Becton Dickinson). Monocytes were identified by forward and sidescatter parameters and by staining with CD14-PerCP (Becton Dickinson). T-cell activation was measured by double staining CD3 and the early activation marker CD69, using flourescein isothiocyanate (FITC)-conjugated anti-CD3 Mab and PE-conjugated anti-CD69 Mab (Becton Dickinson).

IFN- $\gamma$, IL-4 and TNF- $\alpha$ specific Mabs were obtained from Becton Dickinson and IL-12 specific Mab were obtained from PharMingen. All intracellular cytokine specific Mab were FITC conjugated. Cells were analysed by flow cytometry using fluorescenceactivated cell sorter Calibur (Becton Dickinson).

Positive cells were expressed as percentages among the different subsets (CD3+, CD4+, CD8+ T-cells, NK cells and monocytes).

\section{Statistics}

Results are presented as medians (25th-75th percentiles). Comparisons were performed by analysis of variance (ANOVA). All p-values of $<0.05$ were considered as statistically significant.

\section{Results}

Incubation with dust for $1 \mathrm{~h}$ induced a significant production of $\mathrm{TNF}-\alpha$ in the monocytes, i.e. CD14+ peripheral blood cells $(n=6)$, compared to nonstimulated control cells $(\mathrm{p}<0.001$, fig. 1a). Similarly, dust induced a significant IL-12 production in the monocytes compared to the negative control $(\mathrm{p}<0.001$, fig. 1b).

No intracellular cytokine production was observed in lymphocytes after $1 \mathrm{~h}$ of dust incubation. After time kinetic pilot experiments, 22-h incubation, including brefeldin A for the last $10 \mathrm{~h}$, was used. The dust induced significantly higher IFN- $\gamma$ levels in NK cells after 22-h incubation compared to negative controls ( $\mathrm{p}=0.001$, fig. $2 \mathrm{a}$ ). Similarly, NK cells produced significantly more TNF- $\alpha$ compared to negative controls ( $\mathrm{p}<0.05$, fig. 2b). PHA (positive control) also induced high levels of IFN- $\gamma$ and TNF- $\alpha$ in NK cells $(\mathrm{p}<0.001$, fig. $2 \mathrm{a}$ and $\mathrm{b})$.

CD3+ T-cells, CD4+ T-cells and CD8+ cells only produced low levels of IFN- $\gamma$, TNF- $\alpha$ and IL- 4 after dust stimulations (table 1), although the increased production of IFN- $\gamma$ by CD4+ and CD8+ T-cells was significant $(p<0.05$ and $p=0.05$, respectively).

A reduction in dust-induced IFN- $\gamma$ production by NK cells from $6.3-1.8 \%$ was observed in the presence of IL-12 receptor blocking antibodies $(n=6, p=0.017)$, while no difference in the NK cell production of IFN- $\gamma$ was found in the presence of control antibodies (fig. 3). CD69 expression on T-cells was reduced from $19.1 \%(17.1-28.2)$ to $12.2 \%(11.5-20.2)$ when whole blood was stimulated by dust in the presence of IL-12 receptor blocking antibodies (fig. 4). 

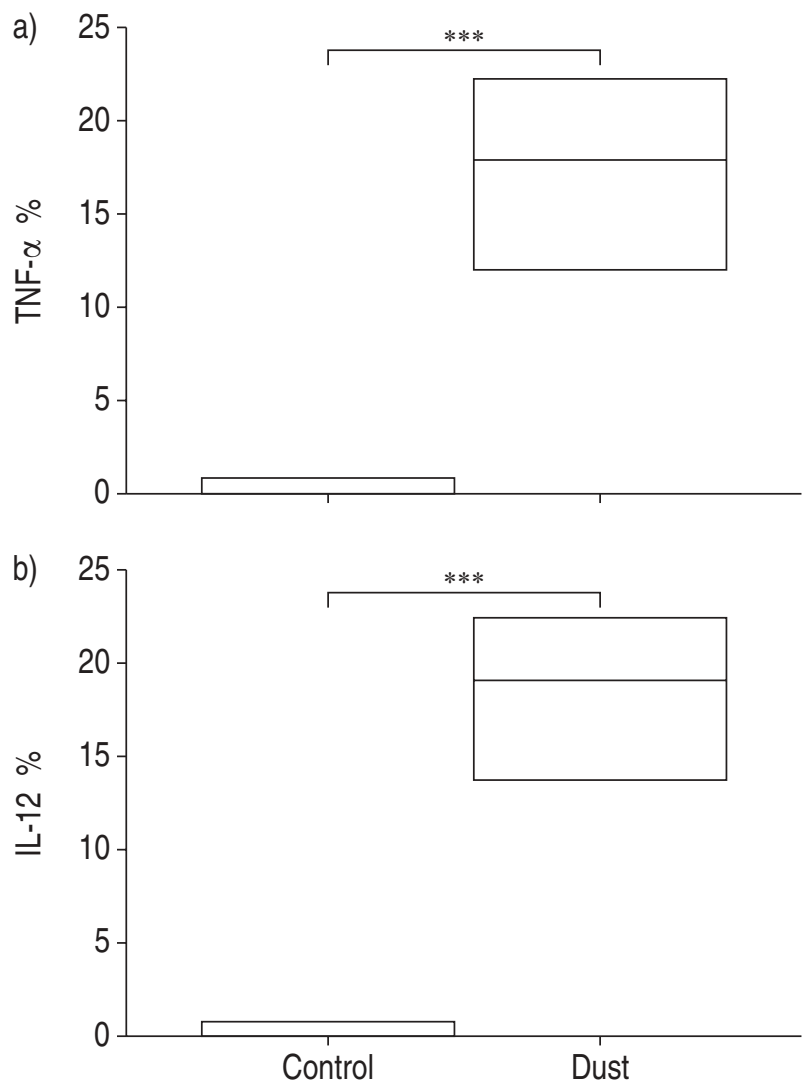

Fig. 1.-Intracellular a) tumour necrosis factor (TNF)- $\alpha$ and b) interleukin (IL)-12 production by CD14+ cells (monocytes) under control conditions (control) or following 1-h incubation with swine dust (dust) $(\mathrm{n}=6)$. Data are presented as median and 25th75th percentiles. ${ }^{* * *}: \mathrm{p}<0.001$.

\section{Discussion}

In the present study, it was shown that monocytes in peripheral whole blood could be stimulated to produce TNF- $\alpha$ and IL-12 after 1-h incubation with dust from a swine confinement facility. No intracellular cytokine production was observed in lymphocytes after incubation with dust at this early time point. However, as seen in the findings of LERTMEMONGKOLCHAI et al. [8], after 22-h incubation with dust, both T-lymphocytes and NK cells produced IFN- $\gamma$ and low levels of TNF- $\alpha$ and IL-4. Furthermore, it was shown that blocking of the IL-12 receptor inhibited the dustinduced IFN- $\gamma$ production by NK cells as well as T-cell activation.
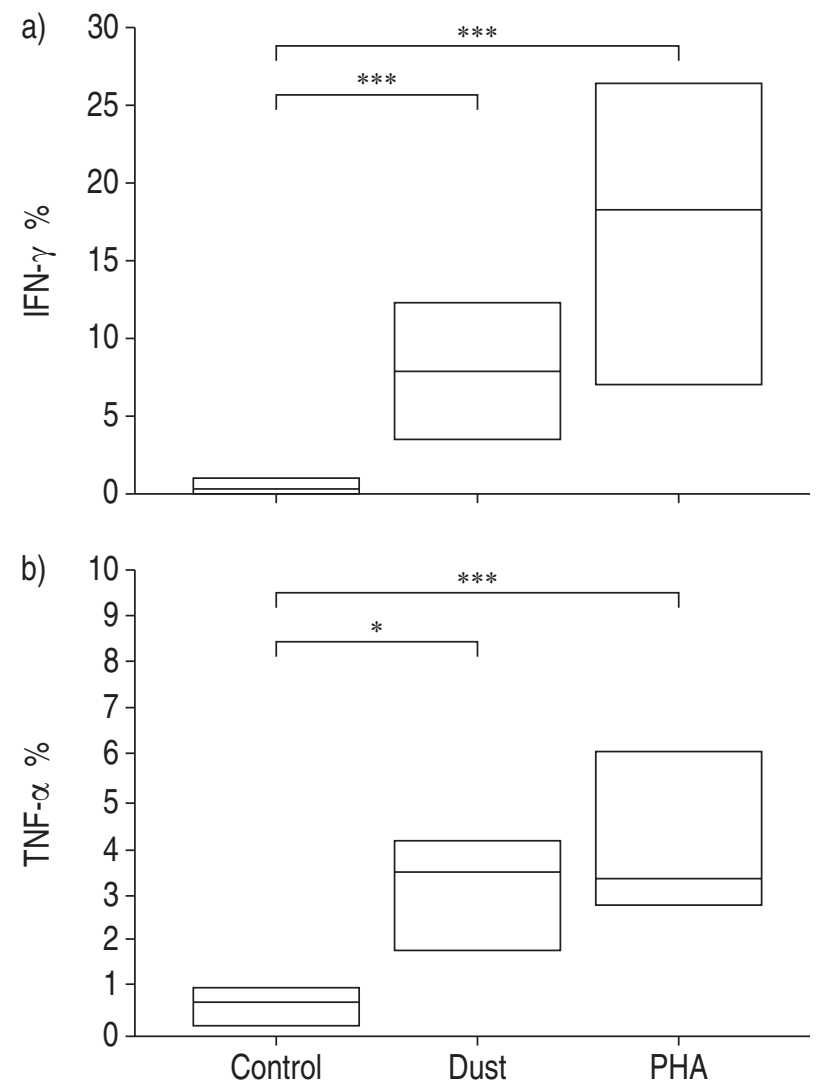

Fig. 2. - Intracellular a) interferon (IFN)- $\gamma$ and b) tumour necrosis factor (TNF)- $\alpha$ production by natural killer cells under control conditions (control), following 22-h incubation with swine dust (dust) and phytohaemagglutinin (PHA). Data are presented as median and 25 th -75 th percentiles $(\mathrm{n}=10)$. $*$ : $\mathrm{p}<0.05 ; * * *: \mathrm{p}<0.001$.

In time kinetic studies of whole blood stimulated with dust, it was found that $1-h$ incubation was enough to induce monocytes to produce TNF- $\alpha$ and IL-12. A previous report [9] also showed a rapid IL-12 production by monocytes after stimulation with Trypanosoma cruzi. The present authors previously found $24 \mathrm{~h}$ of incubation to be optimal with regard to T-cell activation by swine dust. In the present study, the incubation was reduced to $22 \mathrm{~h}$, with only $10 \mathrm{~h}$ brefeldin $\mathrm{A}$, due to the toxicity of this substance.

The present authors have previously reported that dust failed to activate T-cells in peripheral blood depleted from phagocytes [3]. However, plasma separated from dust-incubated whole blood, i.e. conditioned plasma, and added to peripheral blood mononuclear cells over night, was highly capably of

Table 1. - Cytokine production by T-cell subsets after stimulation with organic dust

\begin{tabular}{|c|c|c|c|c|c|c|c|c|c|}
\hline & \multicolumn{3}{|c|}{ IFN- $\gamma$} & \multicolumn{3}{|c|}{$\mathrm{TNF}-\alpha$} & \multicolumn{3}{|c|}{ IL-4 } \\
\hline & Control & p-value & Dust & Control & p-value & Dust & Control & p-value & Dust \\
\hline CD3+ & $0.1(0-0.2)$ & 0.0834 & $2.5(1.7-4.6)$ & $0.3(0.2-0.9)$ & NS & $2.0(0.6-6.0)$ & $0.2(0-0.6)$ & 0.0663 & $1.6(0.9-2.1)$ \\
\hline CD4+ & $0.4(0.2-0.5)$ & 0.0456 & $1.8(1.8-2.3)$ & $1.3(0.9-1.4)$ & NS & $4.0(3.0-6.6)$ & $0.8(0.4-1.6)$ & NS & $3.8(1.8-5.1)$ \\
\hline CD8+ & $0.4(0.3-0.9)$ & 0.0538 & $5.0(4.4-5.2)$ & $1.3(0.4-1.7)$ & NS & $2.8(1.6-3.7)$ & $0.3(0.2-0.5)$ & NS & $2.4(1.0-3.5)$ \\
\hline
\end{tabular}

Data are presented as medians and (25th-75th percentiles). IFN: interferon; TNF: tumour necrosis factor; IL: interleukin; NS: nonsignificant and $\mathrm{p}>0.1 . \mathrm{n}=10$. 


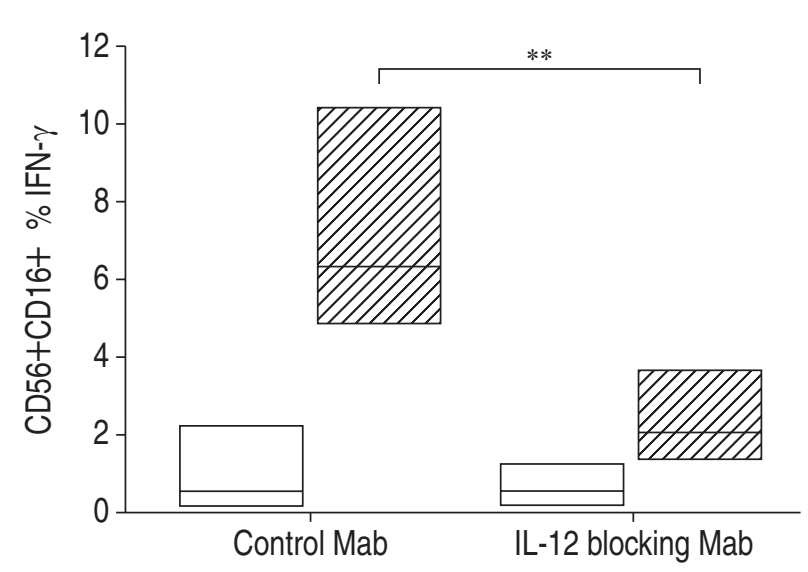

Fig. 3.- Intracellular interferon (IFN)- $\gamma$ production in natural killer cells in blood preincubated with control antibodies (control $\mathrm{Mab}$ ) or blocking antibodies to the interleukin-12 receptor (IL-12 blocking Mab), following 22-h incubation with $(\mathbb{\mathbb { N }})$ or without $(\square)$ organic dust. Data are presented as median and 25th-75th percentiles $(n=6)$. **: $\mathrm{p}=0.01$.

inducing CD69 expression on T-cells (CD3+). Such conditioned plasma contained high levels of IL-12 and IFN- $\gamma$, probably released from phagocytic cells upon stimulation. Thus, IL-12 may be one of the components required for lymphocyte activation by the organic dust. This suggestion is supported by the finding that IL-12 is required for lipopolysaccharide (LPS)-induced activation of NK cells, and that no IL-12 was found in monocyte-depleted cell cultures where the cells were stimulated with LPS [10].

In the present study, whole blood was preincubated for $1 \mathrm{~h}$ with IL-12 receptor blocking Mabs. Used in combination, these two Mabs have an inhibitory effect on the IL-12-mediated functions [7]. A significantly decreased production of IFN- $\gamma$ by NK cells was found when blood was preincubated with IL-12

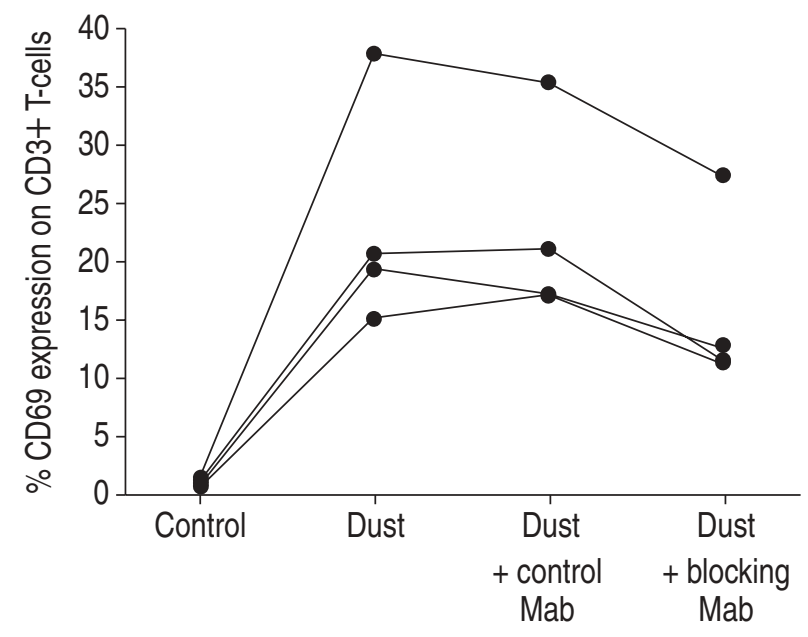

Fig. 4.-CD69 expression on T-cells in blood following 22-h incubation with Roswell Park Memorial Institute (RPMI) medium only (control), with organic dust only (dust), with organic dust and control antibodies (dust+control Mab), or with organic dust and blocking antibodies to the interleukin-12 receptor (dust+ blocking $\mathrm{Mab}$ ). Data are presented as individual CD69 expressions on $\mathrm{CD} 3+\mathrm{T}$-cells. receptor blocking antibodies. Any influence on T-cell IFN- $\gamma$ production was difficult to evaluate due to the low T-cell IFN- $\gamma$ levels. However, preincubated blood with IL-12 receptor blocking antibodies clearly decreased the activation of T-cells, as judged from the reduced CD69 expression.

One mechanism through which monocytes recognise swine dust antigens could be via the CD14 receptor to LPS [11], and the dust is known to contain small amount of LPS [12]. Interestingly, human T-lymphocyte activation by LPS has been shown to be dependent on monocytes, and IL-12 to be one of the important costimulatory factors [13]. In the present study, monocytes rapidly produced TNF- $\alpha$ and IL-12 after incubation with swine dust but when stimulated with LPS only, no distinct IL-12 production was found (data not shown). Thus, other components than LPS are also important for the organic dust stimulation of monocytes.

In conclusion, it has been shown that organic dust can stimulate interleukin-12 production in CD14+ cells and interferon- $\gamma$ production in $\mathrm{T}$ - and natural killer cells. In the presence of dust and interleukin-12 blocking antibodies, the interferon $-\gamma$ production was reduced in natural killer cells as was the CD69 expression on T-cells. In order to clarify the mechanism for in vivo activation of human $\mathrm{T}$ - and natural killer cells further studies will be necessary, including cytokine analyses in bronchoalveolar lavage fluid cells and peripheral blood cells before and after exposure of healthy volunteers to swine dust.

\section{References}

1. Müller-Suur C, Larsson KA, Malmberg PO, Larsson $\mathrm{PH}$. Increased number of activated lymphocytes in human lung following swine dust inhalation. Eur Respir J 1997; 10: 376-380.

2. Müller-Suur C, Larsson PH, Larsson K. T-cell activation by organic dust in vitro. Respir Med 2000; 94: 821-827.

3. Müller-Suur C, Larsson PH, Larsson K, Grunewald J. Lymphocyte activation after exposure to swine dust: a role of humoral mediators and phagocytic cells. Eur Respir J 2002; 19: 104-107.

4. Presky DH, Minetti LJ, Gillessen S, et al. Analysis of the multiple interactions between IL-12 and the high affinity IL-12 receptor complex. J Immunol 1998; 160: 2174-2179.

5. Aste-Amezaga M, D'Andrea A, Kubin M, Trincheieri G. Co-operation of natural killer cell stimulatory factor/interleukin-12 with other stimuli in the induction of cytokines and cytotoxic cell associated molecules in human T and NK cells. Cell Immunol 1994; 156: 480-492.

6. Trinchieri G. Interleukin-12: a cytokine produced by antigen presenting cells with immunoregulatory functions in the generation of T-helper cell type 1 and cytotoxic lymphocytes. Blood 1994; 84: 4008-4027.

7. Wu CY, Warrier RR, Carvajal DM, et al. Biological function and distribution of human interleukin-12 receptor beta chain. Eur J Immunol 1996; 26: 345-350.

8. Lertmemongkolchai G, Cai G, Hunter CA, Bancroft GJ. Bystander activation of CD8+ T cells contributes 
to the rapid production of IFN- $\gamma$ in response to bacterial pathogens. J Immunol 2001; 166: 1097-1105.

9. Frosch S, Kraus S, Fleischer B. Trypanosoma cruzi is a potent inducer of interleukin-12 production in macrophages. Med Microbiol Immunol 1996; 185: 189193.

10. Goodier MR, Londei M. Lipopolysaccharide stimulates the proliferation of human CD56+CD3- NK cell: A regulatory role of monocytes and IL-10. $J$ Immunol 2000; 165: 139-147.

11. Diamond G, Legarda D, Ryan LK. The innate immune response of the respiratory epithelium. Immunol Rev 2000; 173: 27-38.

12. Crock B, Robertson JF, Travers Glass SA, Botheroyd EM, Lacey J, Topping MD. Airborne dust, ammonia, micro-organism, and antigens in pig confinement houses and the respiratory health of exposed farm workers. Am Ind Hyg Assoc J 1991; 52: 271-279.

13. Mattern T, Flad HD, Brade L, Rietschel ET, Ulmer AJ. Stimulation of human T lymphocytes by LPS is MHC unrestricted, but strongly dependent on B7 interactions. J Immunol 1998; 160: 3412-3418. 